\title{
PERFUMES DE CLARICE
}

Rodrigo da Costa Araujo

Para Marina Colasanti, Luziana Simões e Ana, com sutilezas clariceanas 


\section{VELHOS FRASCOS, NOVAS FRAGRÂNCIAS}

Em Clarice Lispector (1920-1977), encontra-se um autêntico projeto literário, verificável a partir da absorção do ocasional, do cotidiano e até do corriqueiro como emissários de sentidos latentes, arquivos de questões irresolvidas, memórias palimpsésticas e sutis. Essas e outras características aparecem no delicado livro De Natura Florum (2021), lançado recentemente pela Global Editora, com ilustrações desenvolvidas por Elena Odriozola, que recebeu o prêmio nacional de ilustração e com projeto gráfico de Alejandro G. Schnetzer. O livro, anteriormente, foi publicado pela primeira vez, em 03 de abril de 1971, no Jornal do Brasil (Rio de Janeiro) e em 1984 fez parte de uma seleção do livro de Crônicas A Descoberta do Mundo.

O texto, à maneira de um delicado e elegante herbário em verso, é estruturado a partir de vinte e quatro verbetes e 56 páginas sobre diferentes espécies de flores. As cinco primeiras são definições botânicas gerais, com uma poética particular. De Natura Florum é, também, espécie de entrada ou introdução ligeira à obra e estilo de Clarice.

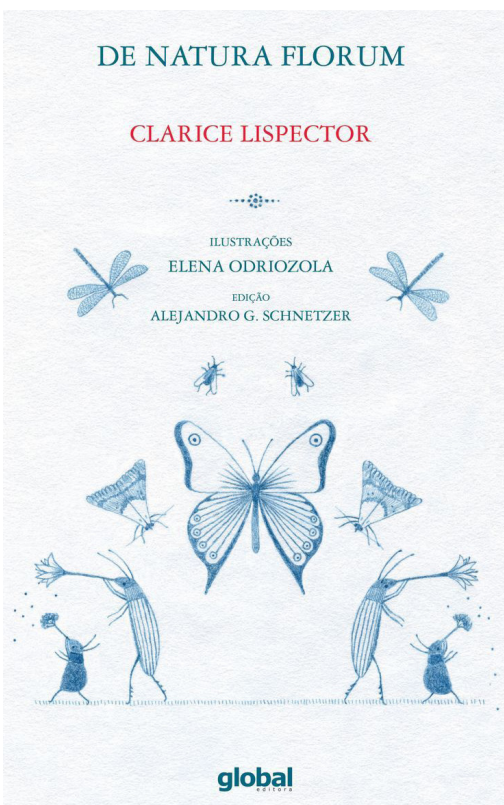

Capa do livro De Natura Florum (2021), de Clarice Lispector 
A força do texto literário e a delicadeza das ilustrações de Elena Odriozola reforçam e realizam a vocação polissêmica do texto e do seu endereçamento à multiplicidade de leituras. Texto e ilustração fazem as flores possuírem contornos refinados como verdadeiras obras de arte. Cada página, como diário íntimo, é uma viagem para os olhos e para o olfato quando se pode sentir, imaginariamente, a suavidade da rosa, a força do cravo, a determinação do girassol, o ar meditativo da violeta, a alegria e cor da margarida.

\author{
Rosa \\ É flor feminina que se dá toda e tanto \\ que para ela só resta alegria \\ de se ter dado. Seu perfume é de um \\ mistério feminino: se profundamente \\ aspirada, toca no fundo coração \\ e deixa o corpo todo perfumado. \\ O modo de ela se abrir em mulher é \\ belíssimo. Suas pétalas têm um gosto \\ bom na boca, é só experimentar.
}

As vermelhas ou as príncipe negro são de grande sensualidade. As amarelas dão alarme alegre. As brancas são a paz. As cor-de-rosa são em geral mais carnudas e têm a cor por excelência. As alaranjadas são sensualmente atraentes. (LISPECTOR, p.03, 2021)

Desses jardins e fragrâncias, da percepção delicada do olfato, da ruptura apaixonada de palavras que podem ser correlatas às flores, nasce um tremor de poesia em cada linha, diante de cada verbete ilustrado ou página. Sempre ensinando a subverter o óbvio, este pequeno dicionário floral, com sua lição generosa, arguta e erudita, texto e ilustração dão vida às espécies botânicas e reverberam, pela leveza da escrita, a sintonia 
para sua subversiva lição de ler o mundo com olhos livres. Orquestrando sentidos, visão e olfato medem o grau de temperatura da fascinação e encanto das flores.

\section{NA REDE DOS TEXTOS, POR UMA ESTÉTICA DO OLFATO}

Pela estética do olfato, ler Clarice, então, é resgatar o jardim floral, a juventude, a vida que comparece em flores para estetizá-la ou erotizá-la sutilmente. $\mathrm{Na}$ efervescência de seus atributos, a vida e as suas emanações já não podem ser ordenadas a não ser pelo olfato. Emaranhadas na trama olfativa, vida e flores se equivalem, como palavra e escrita que se tornam emissários peculiares de mensagens, cujo código adotam as leis do perfumismo.

Autor e leitor, enredados pela linguagem, intertextos e cheiros desempenham modos específicos de leitura. Ler De Natura Florum, de Clarice, agora em livro, é antes de tudo, perceber que esta obra se relaciona com outros textos, crônicas ou romance (Água Viva) - outros fragmentos - e, assim, encaminham-se todos as citações para a construção da escritura desse livro que não se quer escrita nem concluída: " o que te escrevo não tem começo: é uma continuação" (Lispector, 1993, p.53). Clarice, para escrever esta obra, retoma seus textos-fragmentos e, recortando-os e colando-os, estrutura esse De Natura Florum.

Esses mesmos fragmentos De Natura Florum, antes crônica do livro A Descoberta do Mundo, também se configuram como outros fragmentos que (re)aparecem recortados, reescritos e colados às páginas 62, 63 e 64, do livro Água Viva. Nesta perspectiva, ler esta obra já seria assumir o trabalho lúdico e criativo, feito quebra-cabeças ou palimpsesto, de cortar e recortar, mais do que um sentido por outro, mas um fragmento por outro, pelo simples prazer de pôr em movimento tudo o que se pode chamar de texto. O trabalho ou a brincadeira de sobrepor fragmentos resulta numa obra que se constrói por citações acrescidas por outra, que agora, é, também, fragmento visual - a ilustração. 
E ler não seria esse projeto criativo e redundante, não apenas do processo de escrever, mas, e também, do processo de leitura?

\section{DOS PARATEXTOS E PROJETO EDITORIAL}

De Natura Florum é produzido em papel pólen e capa com ilustrações azuis em brochura. A capa e os vinte e quatro verbetes botânicos são ilustrados por Elena Odriozola que utilizam imagens de pessoas, animais e insetos para configurarem a ideia da flor citada, paisagem ou algum sentimento. O tema recai sobre as flores e a natureza, bem como sobre o mundo natural retratados pelo viés subjetivo e poético de Clarice.

O título da obra, paratexto atraente e redigido em latim, remete, pela intertextualidade, à tradição de se classificar a fauna e a flora em nomes latinos. Apesar dessa tradição clássica, percebe-se, também, pelas sutilezas do discurso, a problematização dos conceitos de verbete e de herbário pelo tom poético em que se apresentam ao leitor. A lupa da escritora de Água Viva é uma visão floral materializada e redescoberta pelas visualidades que devolvem ao escritor e ao leitor a visão imperceptível e engrandecida da natureza.

Os intertextos e os intratextos ou jogo das citações na crônica De Natura Florum são reforçados ora pelo subtítulo de "Dicionário", ora pela epígrafe bíblica e indagações com o gênero. $\mathrm{O}$ processo mesmo da escritora em recopiar o fragmento "bíblico" da crônica para dentro da obra, apropriando-se como lhe convém, apaga radicalmente a origem religiosa do texto. Assim, reescrevendo o que lhe interessa, os fragmentos são justapostos e colados no corpo da escritura dessa obra e também estratégia sobre $o$ ato de criar.

Outro paratexto interessante é o texto da quarta capa redigido, em tom de conversa com o leitor, por Marina Colasanti. Anunciado pela ilustração de um beija-flor, o texto, além alcançar outros intertextos da referida crônica com a obra de Clarice Lispector, resvala e aflora outros 
frascos de essências da escritora. Desse recado, confirma-se a sensualidade na escrita, que obedece ao impulso que vem do corpo, intraduzível sem essa linguagem outra, que Clarice recriou, como a transcrição de um sonho sonhado em outra vida e que é a marca de sua literatura.

Entender Marina, pela quarta capa, é sentir em troca com o leitor, algo vindo dos recados das flores e da obra, um olhar que é perscrutado, que não é apenas um reflexo das interrogações desse leitor, mas o processo de uma consciência radicalmente outra. E é ela que fixa esse leitor, vai ao seu encontro, interrogando-o, instigando-o. A obra deseja o leitor. Abrir-se a esse olhar que De Natura Florum lança, é o mesmo que deixar-se ler por Clarice, assim como ela se deixa ler pelas flores e, talvez, seja a maneira mais direta de aproximar-se "claricemente", pelas palavras de Marina e acolhendo as sensações e descobertas que, ao se incorporarem na vida, já aproxima qualquer leitor um pouco mais do selvagem coração de Clarice.

As ilustrações, os verbetes e a obra, no seu conjunto, reforçam a identificação do sujeito-leitor com a natureza que se processa por metamorfose. Identificação e desejo de pertencimento a um universo vegetal integrado na natureza. Personagens-flores ganham variadas especificidades nos espaços sem fronteira onde o humano (e, também, o leitor) e o vegetal se entrecruzam, estabelecendo um processo metamórfico.

O jardim das flores literárias de Clarice representa o universo em sua dimensão imaginária ou lúdica da vida. É palco para o leitor infantojuvenil, poetas ou leitores exercerem a fantasia, local ideal ao surgimento da inspiração poética e para a gênese do trabalho com a linguagem. É aí, entre textos, ilustrações e perfumes que acontecem as brincadeiras poéticas.

Com seu criativo projeto gráfico, De Natura Florum confirma que a imagem, beneficiária das metáforas, explicita-se e multiplica-se como expressão máxima da sua liberdade. A profusão de cores, formas, linhas, cenários, personagens-flores e movimentos produzem impressões sensoriais que disseminam, no nível das linguagens, uma afluência sustentada pelos sentidos. Portanto, isso significa dizer que o visual e 
o verbal se inscrevem em uma mesma linguagem: uma poética que se envereda pelo universo da arte.

De Natura Florum, de Clarice Lispector é uma orquestração, comparações dos sentidos e um elogio para a leitura. Tanto os sentidos como a leitura atendem às piscadelas secretas que as linguagens lançam aos leitores perscrutando seus segredos e os das flores. Eles, através da obra, surgem das "subversões" clariceanas pelo afastamento dos regimes instituídos do sentido, na busca obstinada das vias, por onde, à margem das convenções, retesam-se e vibram as forças da criação (ou dos perfumes?) da poética clariceana.

\section{REFERÊNCIAS}

LISPECTOR, Clarice. De Natura Florum. In: A descoberta do mundo. Rio de Janeiro. Francisco Alves. 1992. pp. 364-366.

_.. Água vViva. Rio de Janeiro. Francisco Alves. 1993. 